\title{
Systematic improvement of isobutanol production from $D$-xylose in engineered Saccharomyces cerevisiae
}

\author{
Peerada Promdonkoy ${ }^{1}$, Wiparat Siripong ${ }^{1}$, Joe James Downes ${ }^{2,3}$, Sutipa Tanapongpipat ${ }^{1}$ \\ and Weerawat Runguphan ${ }^{1 *}$ (D)
}

\begin{abstract}
As the importance of reducing carbon emissions as a means to limit the serious effects of global climate change becomes apparent, synthetic biologists and metabolic engineers are looking to develop renewable sources for transportation fuels and petroleum-derived chemicals. In recent years, microbial production of high-energy fuels has emerged as an attractive alternative to the traditional production of transportation fuels. In particular, the Baker's yeast Saccharomyces cerevisiae, a highly versatile microbial chassis, has been engineered to produce a wide array of biofuels. Nevertheless, a key limitation of S. cerevisiae is its inability to utilize xylose, the second most abundant sugar in lignocellulosic biomass, for both growth and chemical production. Therefore, the development of a robust S. cerevisiae strain that is able to use xylose is of great importance. Here, we engineered S. cerevisiae to efficiently utilize xylose as a carbon source and produce the advanced biofuel isobutanol. Specifically, we screened xylose reductase (XR) and xylose dehydrogenase (XDH) variants from different xylose-metabolizing yeast strains to identify the XR-XDH combination with the highest activity. Overexpression of the selected XR-XDH variants, a xylose-specific sugar transporter, xylulokinase, and isobutanol pathway enzymes in conjunction with the deletions of PHO13 and GRE3 resulted in an engineered strain that is capable of producing isobutanol at a titer of $48.4 \pm 2.0 \mathrm{mg} / \mathrm{L}$ (yield of $7.0 \mathrm{mg} / \mathrm{g} \mathrm{D}$-xylose). This is a 36-fold increase from the previous report by Brat and Boles and, to our knowledge, is the highest isobutanol yield from D-xylose in a microbial system. We hope that our work will set the stage for an economic route for the production of advanced biofuel isobutanol and enable efficient utilization of lignocellulosic biomass.
\end{abstract}

Keywords: Yeast, Xylose utilization, Advanced biofuel, Isobutanol, Metabolic engineering

\section{Introduction}

Renewable fuels have received significant interest in recent years due to environmental concerns and unsustainable energy demands (Peralta-Yahya et al. 2012; Liao et al. 2016). Microbial production of advanced fuels has emerged as a viable alternative to the traditional petroleum-based transportation fuels that are responsible for the emission of greenhouse gases (Flores et al. 2019). Recent examples include the production of long

\footnotetext{
*Correspondence: weerawat.run@biotec.or.th

${ }^{1}$ National Center for Genetic Engineering and Biotechnology, 113

Thailand Science Park, Paholyothin Road, Klong 1, Klong Luang,

Pathumthani 12120, Thailand

Full list of author information is available at the end of the article
}

chain alkanes and fatty acid ethyl esters (FAEE) as diesel replacements and short-chain alkanes and isoprenoidbased biofuels as gasoline replacements (Peralta-Yahya et al. 2011; Choi and Lee 2013; Runguphan and Keasling 2014; Buijs et al. 2015). In many of these examples, the yeast $S$. cerevisiae has been the host of choice due to its ideal properties, namely: (1) high tolerance to many industrial stresses, such as low $\mathrm{pH}$ and high osmotic pressure; (2) high tolerance to the desired biofuel products; (3) resistance to phage infection; and (4) availability of genetic tools and "omics" data for bottoms-up strain engineering. However, despite its potential as a production host, $S$. cerevisiae suffers from one significant drawback: it is unable to utilize xylose, a C5 sugar that is a 
major component $(\sim 30-40 \%)$ of lignocellulosic biomass (Kwak and Jin 2017).

Increasingly, the use of starch or the sucrose fractions of agricultural crops as the carbon substrates for biomass conversion has become less attractive due to environmental, economical and ethical considerations (Mosier et al. 2005). Instead, lignocellulosic biomass, such as agricultural residues and energy crops, offers a cheap and renewable alternative carbon source for the microbial production of biofuels. Since xylose is the second most abundant component of lignocellulosic biomass, enabling the yeast S. cerevisiae to efficiently utilize xylose and convert it into biofuels is of great importance and has been the focus of intense and highly competitive research ( $\mathrm{Li}$ et al. 2019).

An extensive body of work has resulted in engineered strains that are capable of producing near-theoretical yields of ethanol from pure xylose and xylose-containing biomass (Zhang et al. 2016). To create such a strain, a xylose assimilation pathway is introduced into S. cerevisiae, enabling the resulting strain to convert xylose into xylulose and then xylulose-5-phosphate, a starting metabolite to the non-oxidative Pentose Phosphate Pathway (PPP) (Fig. 1) (Moyses et al. 2016). The two products of the PPP, glyceraldehyde-3-phosphate and fructose6-phosphate, then enter glycolysis, producing pyruvate and leading to ethanol production.

Two distinct pathways exist in xylose-fermenting organisms for the conversion of xylose to xylulose: the xylose reductase-xylitol dehydrogenase (XR-XDH) pathway in yeast and aerobic fungal species and the xylose isomerase (XI) pathway in bacteria and anaerobic fungal. In the XR-XDH pathway, XR first reduces xylose to xylitol using NADPH and/or NADH as a cofactor. $\mathrm{XDH}$ then converts xylitol into xylulose with a specific cofactor preference for $\mathrm{NAD}^{+}$. Because of the dual cofactor preference, the redox imbalance hinders successful implementation of the XR-XDH pathway. Conversely, in the XI pathway, XI converts xylose to xylulose without requiring any cofactor. However, as XI enzymes tend to have lower catalytic efficiency compared to XR$\mathrm{XDH}$ enzymes, they are less attractive for industrial-scale applications (Kwak and Jin 2017).

Although microbial ethanol fermentation has played an important role in the transition from conventional fossil fuels to bio-based fuels, ethanol is not an ideal gasoline replacement due to its poor physicochemical properties (Generoso et al. 2015). Specifically, ethanol has low energy density ( $\sim 70 \%$ of the energy content of gasoline), high tendency to absorb water, and high vapor pressure. In contrast, higher and branched-chain alcohols, such as butanol and isobutanol, have superior energy density and are more compatible with the existing distribution and storage infrastructures (Lamsen and Atsumi 2012). Moreover, branched-chain alcohols have higher octane numbers compared with their straight-chain counterparts and are therefore ideal gasoline substitutes for high performance petrol engines.

To produce branched-chain and higher alcohols in a non-native producer, Atsumi and coworkers devised a strategy which involves "hijacking" the native amino acid metabolism of the host organism and diverts the amino acid intermediate to the 2-keto acid degradation pathway for higher alcohol production (Atsumi et al. 2008). In the L-valine biosynthetic pathway, acetolactate synthase (Ilv2) condenses two molecules of pyruvate to 2 -acetolactate, which is then reduced to 2,3-dihydroxyisovalerate by acetohydroxyacid reductoisomerase (Ilv5). Next, 2,3-dihydroxyisovalerate is converted to 2-ketoisovalerate, a key intermediate in L-valine biosynthesis, by dihydroxyacid dehydratase (Ilv3). In the ketoacid degradation pathway, 2-ketoisovalerate is converted to isobutanal by introducing a heterologous ketoacid decarboxylase (kivD) from the bacterium Lactococcus lactis or by overexpression of the endogenous decarboxylase (Aro10). The resulting aldehyde is then reduced by an alcohol dehydrogenase (Adh7 or Adh2) from S. cerevisiae to the final alcohol products, including isobutanol. Though the original work was done in E. coli, several labs have since applied this strategy to produce isobutanol in many organisms including the cyanobacterium Synechococcus elongatus PCC7942, the soil bacterium Ralstonia eutropha, and more recently, the methylotrophic yeast Pichia pastoris (Atsumi et al. 2009; Lu et al. 2012; Siripong et al. 2018).

While production of isobutanol from glucose in the yeast system is well established, we found only one previous report of branched-chain alcohol production from xylose in S. cerevisiae (Brat and Boles 2013). In the study, Brat and Boles overexpressed the xylose isomerase XylA from Clostridium phytofermentans along with isobutanol pathway enzymes in S. cerevisiae. The engineered strain produced isobutanol at a yield of $0.16 \mathrm{mg} / \mathrm{g}$ xylose, well below the reported yields from glucose of up to $16 \mathrm{mg} / \mathrm{g}$ glucose (Matsuda et al. 2013).

Here, we improved upon this previous work and engineered an efficient isobutanol producing strain of S. cerevisiae. Specifically, we first screened XR-XDH pathway genes from various xylose-utilizing species to identify an optimal XR-XDH gene combination. We then integrated the isobutanol pathway, which comprises the first portion of the endogenous L-valine biosynthesis and keto-acid degradation pathway. Next, we disrupted two endogenous genes that have previously been shown to improve xylose assimilation in $S$. cerevisiae. Finally, we finetuned the expression level of the each gene in the xylose 


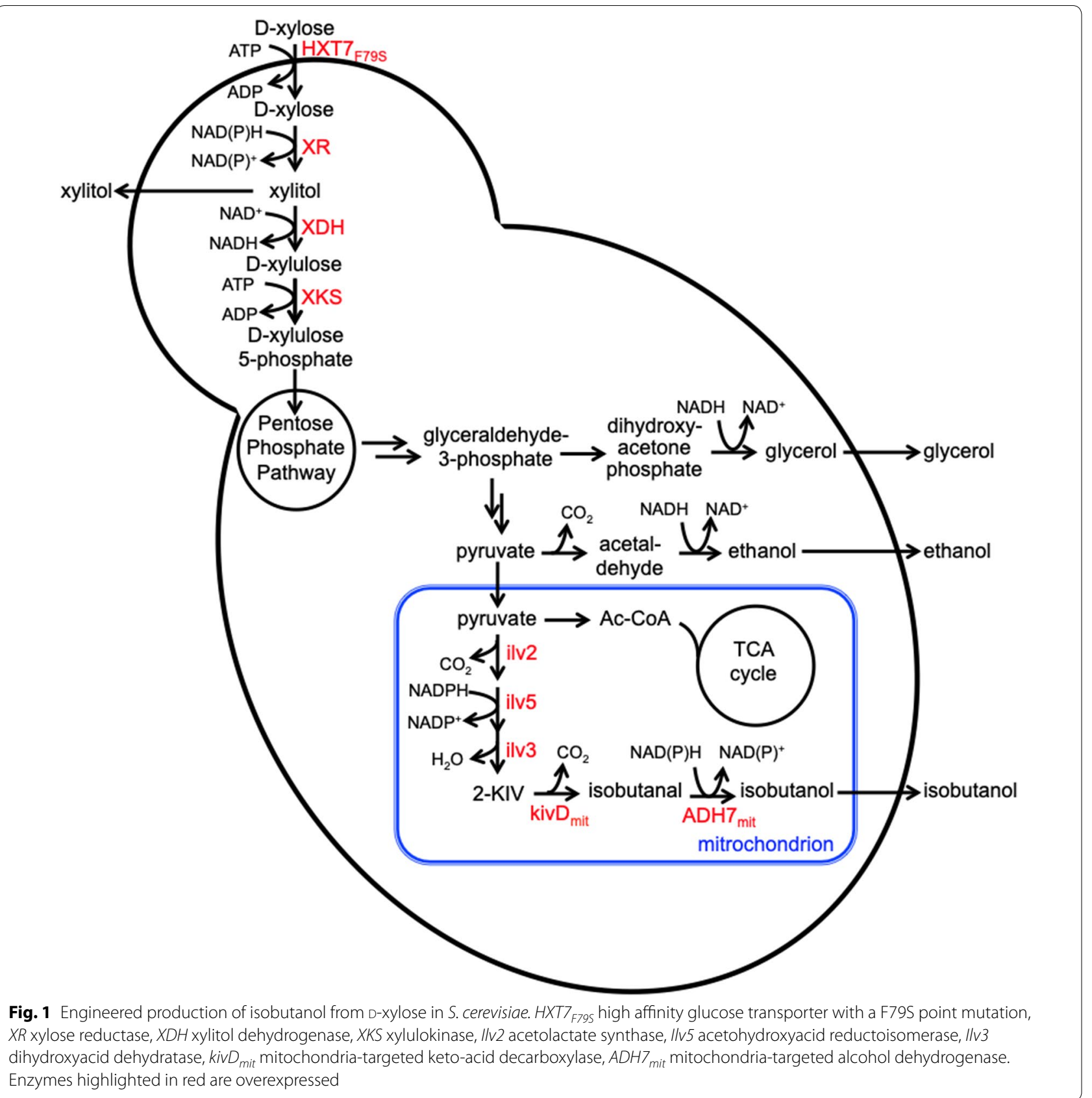

utilization pathway and isobutanol pathway. We envision that our yeast platform will pave the way for a scalable and economic route to the production of biofuels utilizing environmentally sensitive and less carbon-intensive agricultural wastes and energy crops.

\section{Methods}

Yeast strain, media and transformation

The yeast strains used in this study were constructed from BY4742 [derivative of S288C (Mat $\alpha$; his3 41 ; leu $2 \Delta 0 ;$ lys $2 \Delta 0 ;$ ura $3 \Delta 0$ )] (Table 1 ). The plasmids used in this study were generated from the pRS416, pRSII416 and pRSII426 vector series (Additional file 1: Table S1) (Chee and Haase 2012). pRS416 and pRSII416 contain the yeast CEN6/ARS4 origin of replication, which results in transformants with a low copy plasmid number (1 copy per cell). In contrast, pRSII426 contains the yeast $2 \mu$ origin of replication, which allows autonomous replication of the plasmids and results in 
Table 1 Strains generated in this study

\begin{tabular}{|c|c|c|c|}
\hline Strain name & Genotype & Description & References \\
\hline BY4742 & Mat a; his $3 \Delta 1$; leu2 $\Delta 0$; lys $2 \Delta 0$; ura3 $\Delta 0$ & Laboratory strain & $\begin{array}{l}\text { Baker } \\
\text { Brach- } \\
\text { mann } \\
\text { et al. } \\
\text { (1998) }\end{array}$ \\
\hline PWY0013 & BY4742 ARS208::P TEFT - SSXKS; YMRWA15::P $P_{\text {TEF } 1}-$ HXTF79S & $\begin{array}{l}\text { BY4742 overexpressing XKS from Scheffersomyces stipitis, HXT7_ } \\
\text { F79S from Saccharomyces cerevisiae }\end{array}$ & This study \\
\hline PWY1113 & PWY0013 ARS308::: $P_{\text {TEF }}-C t X Y L 1 ; A R S 720:: P_{\text {TEF1 }}-C t X Y L 2$ & $\begin{array}{l}\text { PWY0013 overexpressing XYL1 and XYL2 from Candida tropi- } \\
\text { calis }\end{array}$ & This study \\
\hline PWY1213 & PWY0013 ARS308::: $P_{\text {TEF }}$-CSXYL1; ARS720:: $P_{\text {TEF }}$-CTXYL2 & $\begin{array}{l}\text { PWY0013 overexpressing XYL1 from Candida shehatae and } \\
\text { XYL2 from C. tropicalis }\end{array}$ & This study \\
\hline PWY1313 & 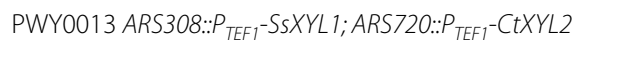 & $\begin{array}{l}\text { PWY0013 overexpressing XYL1 from S. stipitis and XYL2 from C. } \\
\text { tropicalis }\end{array}$ & This study \\
\hline PWY1413 & PWY0013 ARS308:: $P_{\text {TEF } 1}-S p X Y L 1.1 ;$ ARS720:: $P_{\text {TEF } 1}-C t X Y L 2$ & $\begin{array}{l}\text { PWY0013 overexpressing XYL1.1 from Spathaspora passali- } \\
\text { darum and XYL2 from C. tropicalis }\end{array}$ & This study \\
\hline PWY1513 & PWY0013; ARS308::P $P_{\text {TEF } 1}-S p X Y L 1.2 ; A R S 720:: P_{\text {TEF } 1}-C t X Y L 2$ & $\begin{array}{l}\text { PWY0013 overexpressing XYL1.2 from S. passalidarum and XYL2 } \\
\text { from C. tropicalis }\end{array}$ & This study \\
\hline PWY2113 & 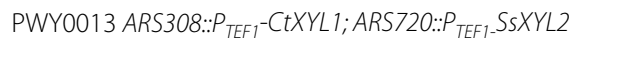 & $\begin{array}{l}\text { PWY0013 overexpressing XYL1 from C. tropicalis and XYL2 from } \\
\text { S. stipitis }\end{array}$ & This study \\
\hline PWY2213 & PWY0013 ARS308:: $P_{\text {TEF } 1}-C S X Y L 1 ;$ ARS720:: $P_{\text {TEF } 1}-S S X Y L 2$ & $\begin{array}{l}\text { PWY0013 overexpressing XYL1 from C. shehatae and XYL2 from } \\
\text { S. stipitis }\end{array}$ & This study \\
\hline PWY2313 & PWY0013 ARS308::P $P_{\text {TEF } 1 \text { SSXYL1; ARS720::P }}$ TEF1 - -SSXYL2 & PWY0013 overexpressing XYL1 and XYL2 from S. stipitis & This study \\
\hline PWY2413 & PWY0013 ARS308::: TEF $1_{1}-S p X Y L 1.1 ; A R S 720:: P_{\text {TEF } 1}-S S X Y L 2$ & $\begin{array}{l}\text { PWY0013 overexpressing XYL1.1 from S. passalidarum and XYL2 } \\
\text { from S. stipitis }\end{array}$ & This study \\
\hline PWY2513 & PWY0013 ARS308::: $P_{\text {TEF } 1}-S p X Y L 1.2 ;$ ARS720::P TEF 1 $-S S X Y L 2$ & $\begin{array}{l}\text { PWY0013 overexpressing XYL1.2 from S. passalidarum and XYL2 } \\
\text { from S. stipitis }\end{array}$ & This study \\
\hline PWY3113 & 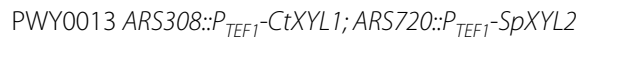 & $\begin{array}{l}\text { PWY0013 overexpressing XYL1 from C. tropicalis and XYL2 from } \\
\text { S. passalidarum }\end{array}$ & This study \\
\hline PWY3313 & 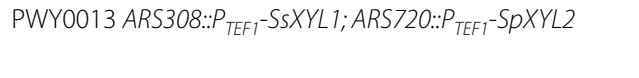 & $\begin{array}{l}\text { PWY0013 overexpressing XYL1 from S. stipitis and XYL2 from S. } \\
\text { passalidarum }\end{array}$ & This study \\
\hline PWY3413 & PWY0013 ARS308::PTEF1-SpXYL1.1;ARS720::PTEF1-SpXYL2 & PWY0013 overexpressing XYL1.1 and XYL2 from S. passalidarum & This study \\
\hline PWY3513 & PWY0013 ARS308:: $P_{\text {TEF } 1}-S p X Y L 1.2 ; A R S 720:: P_{\text {TEF } 1}-S p X Y L 2$ & PWY0013 overexpressing XYL1.2 and XYL2 from S. passalidarum & This study \\
\hline PWY1123 & PWY1113 GRE3 & PWY1113 with GRE3 deleted & This study \\
\hline PWY1223 & PWY1213 GRE3 & PWY1213 with GRE3 deleted & This study \\
\hline PWY2323 & PWY2313 GRE3 & PWY2313 with GRE3 deleted & This study \\
\hline PWY3323 & PWY3313 GRE3 & PWY2313 with GRE3 deleted & This study \\
\hline PWY1133 & PWY1123 YORW $22:: P_{T D H 3}-L / k i v D m t-T 2 A-S C A D H 7 m t$ & $\begin{array}{l}\text { PWY1 } 123 \text { overexpressing ADH7 from S. cerevisiae, and kivD } \\
\text { from L. lactis }\end{array}$ & This study \\
\hline PWY1143 & PWY1133 ARS1309::P TEFI-SCIV2-T2A-SCIlv5-T2A-Scllv3 & PWY1133 overexpressing IIv2, IIv5, IIv3 from S. cerevisiae & This study \\
\hline PWY1153 & PWY1143 PHO13ム & PWY1143 with PHO13 deleted & This study \\
\hline PWY2333 & PWY2323 YORWA22:::PTDH3 -LIkivDmt-T2A-SCADH7mt & $\begin{array}{l}\text { PWY2323 overexpressing ADH7 from S. cerevisiae, and kivD } \\
\text { from L. lactis }\end{array}$ & This study \\
\hline PWY2343 & PWY2333 ARS1309::P TEFI-SCIV2-T2A-SCIVv5-T2A-Scllv3 & PWY2333 overexpressing I/v2, IIv5, IIv3 from S. cerevisiae & This study \\
\hline PWY2353 & PWY2343 PHO13ム & PWY2343 with PHO13 deleted & This paper \\
\hline
\end{tabular}

transformants with a high plasmid copy number (10-40 copies per cell) (Schneider and Guarente 1991).

Yeast and bacterial strains were stored in $25 \%$ glycerol at $-80{ }^{\circ} \mathrm{C}$. E. coli was grown in Luria-Bertani medium. Ampicillin at $100 \mu \mathrm{g} / \mathrm{mL}$ was added to the medium when required. Yeast strain without plasmid was cultivated in YPD medium $(10 \mathrm{~g} / \mathrm{L}$ yeast extract, $20 \mathrm{~g} / \mathrm{L}$
Bacto Peptone and $20 \mathrm{~g} / \mathrm{L}$ glucose). Selection of yeast transformants with URA3 was done on a yeast selective medium (6.7 g/L of Yeast Nitrogen Base (Difco), $20 \mathrm{~g} / \mathrm{L}$ glucose, and a mixture of appropriate nucleotide bases and amino acids with Uracil dropouts (CSM-URA). Yeast cells were cultivated at $30{ }^{\circ} \mathrm{C}$ in $50 \mathrm{~mL}$ Falcon tubes or $250 \mathrm{~mL}$ Erlenmeyer flasks closed with cotton plug and shaken at $250 \mathrm{rpm}$. 
$\mathrm{XR}$ and $\mathrm{XH}$ candidate genes were amplified from genomic DNA [in the cases where the strains are available in the Thailand Bioresource Research Center (TBRC)] or synthesized by Genscript. The individual genes were placed behind the $\mathrm{P}_{\mathrm{TEF} 1}$ promoter and separately integrated into the yeast genome at specific targets (Reider Apel et al. 2017). Gene knockouts were generated using a previously reported gene disruption cassette in $\mathrm{S}$. cerevisiae (Gueldener et al. 2002). Gene disruption cassettes containing the URA3 selectable marker flanked by loxP sites (obtained by PCR of the pUG72 plasmid) were produced with 42 base pairs of homology on either side of each target integration site. Oligonucleotide primers used for PCR, cloning, chromosomal integration and gene knock-outs in this study are included in Additional file 1. Yeast cells were transformed using the $\mathrm{Li} / \mathrm{Ac} /$ PEG method as previously described (Gietz and Schiestl $2007 \mathrm{a}, \mathrm{b})$. Following yeast transformations, colonies were selected on selective medium lacking uracil and confirmed via PCR. The marker gene (URA3) was removed by overexpressing the Cre recombinase to excise the selection marker between the loxP sites in the disruption cassette. This enables subsequent rounds of genomic integrations. Cre recombinase was expressed using the inducible GAL1 promoter on plasmid pSH62 (Hegemann and Heick 2011). The strain harboring pSH62 was grown in SD medium plus $1 \mathrm{~g} / \mathrm{L}$ 5-fluoroorotic acid to encourage loss of the URA3 (Boeke et al. 1984). To verify the genetic stability of the engineered strains, their genomic DNA was isolated (Promega Wizard Genomic DNA Purification kit) and then subjected to a diagnostic PCR amplification that amplified regions both upstream and downstream of the integration/deletion sites.

\section{Plasmid construction}

Plasmid pRS416Tef1-SsXKS: XKS (accession number: XM_001387288) was amplified from S. stipitis BCC47637 genomic DNA using primers S1 and S2. The SsXKS amplicon was ligated to the BamHI/EcoRI site of p416Tef1-Ura3 (Runguphan and Keasling 2014) to yield pRS416Tef1-SsXKS.

Plasmid pRS416Tef1-HXT7_F79S: HXT7_F79S (accession number: NM_001180650) was amplified from $S$. cerevisiae BY4742 genomic DNA as two fragments using primers S3 and S4, and S5 and S6. S4 and S5 primers contain the point mutation required for the amino acid substitution. The two fragments were placed behind the $\mathrm{P}_{\text {TEF1 }}$ promoter in p416Tef1-Ura3 to form pRS416Tef1HXT7_F79S using homologous recombination in yeast.

Plasmid pRS416Tef1-CtXYL1: CtXYL1 (accession number: MF045434) was amplified from C. tropicalis BCC59435 genomic DNA using primers S7 and S8. The
CtXYL1 amplicon was ligated to the BamHI/EcoRI site of p416Tef1-Ura3 to yield pRS416Tef1-CtXYL1.

Plasmid pRS416Tef1-CsXYL1: CsXYL1 (accession number: MN200231) was synthesized by Genscript and was ligated into the BamHI/EcoRI site of p416Tef1-Ura3 to yield pRS416Tef1-CsXYL1.

Plasmid pRS416Tef1-SsXYL1: SsXYL1 (accession number: HM769331) was amplified from S. stipitis BCC47637 genomic DNA using primers S9 and S10. The SsXYL1 amplicon was ligated to the BamHI/SmaI site of p416Tef1-Ura3 to yield pRS416Tef1-SsXYL1.

Plasmid pRS416Tef1-SpXYL1.1: SpXYL1.1 (accession number: MN200233) was synthesized by Genscript and was ligated into the BamHI/EcoRI site of p416Tef1-Ura3 to yield pRS416Tef1-SpXYL1.1.

Plasmid pRS416Tef1-SpXYL1.2: SpXYL1.2 (accession number: MN200234) was synthesized by Genscript and was ligated into the BamHI/EcoRI site of p416Tef1-Ura3 to yield pRS416Tef1-SpXYL1.2.

Plasmid pRS416Tef1-CtXYL2: CtXYL2 (accession number: JN631039) was amplified from C. tropicalis BCC59435 genomic DNA using primers S11 and S12. The CtXYL2 amplicon was ligated to the SacII/EcoRI site of p416Tef1-Ura3 to yield pRS416Tef1-CtXYL2.

Plasmid pRS416Tef1-SsXYL2: SsXYL2 (accession number: HM769332) was amplified from S. stipitis BCC47637 genomic DNA using primers S13 and S14. The SsXYL2 amplicon was ligated to the SacII/EcoRI site of p416Tef1Ura3 to yield pRS416Tef1-SsXYL2.

Plasmid pRS416Tef1-SpXYL2: SpXYL2 (accession number: MN200232) was synthesized by Genscript and was ligated into the SacII/EcoRI site of p416Tef1-Ura3 to yield pRS416Tef1-SpXYL2.

Plasmid pUG72-TDH3-LlkivDmit-2A-ScADH7mit: $\mathrm{P}_{\mathrm{TDH} 3}$ promoter (accession number: NM_00118132) and ADH7 (accession number: NM_001178812) were amplified from S. cerevisie BY4742 genomic DNA using primers S15 and S16, and S17 and S18, respectively. LlkivD (codon-optimized for S. cerevisiae expression; accession number: MN200235) was synthesized by Genscript and provided in pUC57 vector. The gene was amplified from pUC57-LlkivD using primers S19 and S20. The three amplicons $\left(\mathrm{P}_{\mathrm{TDH} 3}\right.$, LlkivD, $\left.\mathrm{ADH7}\right)$ were joined together with pUG72 to form pUG72-TDH3-LlkivD2A-ScADH7. To add the mitochondria signal peptide sequence to LlkivD and ADH7, $\mathrm{P}_{\mathrm{TDH} 3}$, LlkivD, ADH7 were amplified from pUG72-TDH3-LlkivD-2A-ScADH7 using primer S15 and S21, S22 and S23, and S24 and S18, respectively. The three amplicons $\left(\mathrm{P}_{\mathrm{TDH} 3}\right.$, LlkivDmit, ADH7mit) were joined together with pUG72 to form pUG72-TDH3-LlkivDmit-2A-ScADH7mit.

Plasmid pRS416Tef1-ScIlv2-2A-ScIlv5-2A-ScIlv3: Ilv2 (accession number: NM_001182608), Ilv5 (accession 
number: NM_001182244) and Ilv3 (accession number: NM_001181674) were amplified from S. cerevisiae BY4742 genomic DNA using primers S25 and S26, S27 and S28, and S29 and S30, respectively. The three amplicons were placed behind the $\mathrm{P}_{\text {TEF1 }}$ promoter in $\mathrm{p} 416 \mathrm{Tef1}$ Ura3 to form pRS416Tef1-ScIlv2-2A-ScIlv5-2A-ScIlv3 using homologous recombination in yeast.

Plasmid pRSII416-TDH3-LlkivDmit-2A-ScADH7mit: The TDH3-LlkivDmit-2A-ScADH7mit fragment was amplified from pUG72-TDH3-LlkivDmit-2A-ScADH7mit using primers S31 and S32. The amplicon was ligated into the ApaI/SmaI site of pRSII416 to yield pRSII416-TDH3-LlkivDmit-2A-ScADH7mit.

Plasmids pRSII426Tef1-ScHXT7_F79S, pRSII426Tef1SsXYL1, pRSII426Tef1-SsXYL2 and pRSII426Tef1ScIlv2-2A-ScIlv5-2A-ScIlv3-Ura3: The $\mathrm{P}_{\mathrm{TEF} 1}$-gene- $\mathrm{T}_{\mathrm{CYC} 1}$ cassette for each of the gene was amplified from its corresponding low-copy plasmid using primers S33 and S34. Each amplicon was individually ligated to the NotI/SacI site of pRSII426 to yield the high-copy plasmid.

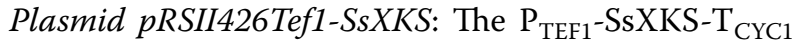
cassette was amplified from pRS416Tef1-SsXKSUra3 using primers S35 and S36. The amplicon was ligated into the PstI/NotI site of pRSII426 to yield pRSII426Tef1-SsXKS.

Plasmid pRSII426-TDH3-LlkivDmit-2A-ScADH7mit: The $\mathrm{P}_{\mathrm{TDH} 3}$-LlkivDmit-2A-ScADH7mit-T ${ }_{\mathrm{CYC1}}$ cassette was amplified from pRSII416-TDH3-LlkivDmit2A-ScADH7mit using primers S37 and S34. The amplicon was ligated into the NotI/SacI site of pRSII426 to yield pRSII426-TDH3-LlkivDmit-2A-ScADH7mit.

\section{Screening of XR-XDH variants in S. cerevisiae}

Engineered strains harboring different combination of $\mathrm{XR}-\mathrm{XDH}$ variants were pre-cultured in $5-\mathrm{mL}$ aliquots in SD selective yeast medium $(6.7 \mathrm{~g} / \mathrm{L}$ of Yeast Nitrogen Base (Difco), $20 \mathrm{~g} / \mathrm{L}$ glucose, and a mixture of appropriate nucleotide bases and amino acids (CSM) overnight and used to inoculate $10 \mathrm{~mL}$ SX selective yeast medium ( $6.7 \mathrm{~g} / \mathrm{L}$ of Yeast Nitrogen Base (Difco), $20 \mathrm{~g} / \mathrm{L}$ xylose, and a mixture of appropriate nucleotide bases and amino acids (CSM) to achieve an initial optical density of 0.05 at $600 \mathrm{~nm}\left(\mathrm{OD}_{600}\right)$. The cultures were grown at $30{ }^{\circ} \mathrm{C}$ and $250 \mathrm{rpm}$ in an orbital shaking incubator. Samples were taken at 24,48 and $72 \mathrm{~h}$ time points for $\mathrm{OD}_{600}$ measurement.

\section{Quantification of isobutanol production in engineered strains}

Engineered yeast strains were grown overnight in $5 \mathrm{~mL}$ of SD selective yeast medium in a $50 \mathrm{~mL}$ Falcon tube. Then, the cultures were inoculated into $50 \mathrm{~mL}$ of SX selective yeast medium in 250-mL flask cultures to achieve an initial $\mathrm{OD}_{600}$ of 0.05 . The cultures were grown at $30{ }^{\circ} \mathrm{C}$ and $250 \mathrm{rpm}$ in an orbital shaking incubator. Samples were taken at 72 and $144 \mathrm{~h}$ to determine $\mathrm{OD}_{600}$, biomass, extracellular metabolites and production of higher alcohols. The amount of isobutanol and other extracellular metabolites were determined using high-performance liquid chromatography (HPLC) as previously reported with small modifications (Avalos et al. 2013; Siripong et al. 2018). Briefly, $1 \mathrm{~mL}$ of culture was centrifuged at $18,000 \mathrm{~g}$ for $5 \mathrm{~min}$ and the supernatant was filtered through $0.2 \mu \mathrm{m}$ nylon syringe filter (Filtrex). The purified sample was then applied to an Agilent 1100 series HPLC equipped with an Aminex HPX-87H ion exchange column (Biorad). The LC program was performed using $5 \mathrm{mM} \mathrm{H}_{2} \mathrm{SO}_{4}$ as the solvent at a flow rate of $0.68 \mathrm{~mL} /$ min for $30 \mathrm{~min}$. The column was maintained at $60^{\circ} \mathrm{C}$. All metabolites were detected with Agilent 1200 series DAD and RID detectors.

\section{Results \\ Screening of optimal xylose reductase-xylose dehydrogenase pathway genes}

To engineer $S$. cerevisiae with the ability to grow on xylose, we first integrated the xylose-specific variant of the sugar transporter $H X T 7\left(H X T 7_{\mathrm{F} 79 \mathrm{~S}}\right)$ and a copy of the S. stipitis xylulokinase gene (XYL3) into BY4742, a laboratory strain of $S$. cerevisiae. While a gene encoding xylulokinase is present in S. cerevisiae (i.e. XKS1), its expression level is insufficient for efficient conversion of xylulose to xylulose-5-phosphate (Johansson et al. 2001). The resulting strain, PWY0013, while still unable to grow in selective medium containing xylose as the sole carbon source, provided the necessary background for XR-XDH screening (Fig. 1, Table 2). We screened different XR and $\mathrm{XDH}$ candidate enzymes that have demonstrated high activity in S. cerevisiae (Kim et al. 2013; Guo et al. 2016; $\mathrm{Li}$ et al. 2016). For XR, these are CtXYL1 from Candida tropicalis, CsXR from Candida shehatae, SsXYL1 from S. stipitis, SpXYL1.1 and SpXYL1.2 from Spathaspora passalidarum. The first four enzymes prefer NADPH as the redox cofactor while the last enzyme prefers NADH. For $\mathrm{XDH}$, these are $\mathrm{CtXDH}$ from C. tropicalis, SsXYL2 from S. stipitis, and SpXYL2 from S. passalidarum. To ensure robust and stable expression of these genes, we integrated the individual $\mathrm{XR}$ and $\mathrm{XDH}$ constructs into the ARS308 and ARS720 sites, respectively. These chromosomal integration sites have previously been shown to lead to high expression level of the inserted gene (Reider Apel et al. 2017).

The engineered strains exhibited superior cell growth when compared to strains BY4742 (Baker Brachmann et al. 1998) and PWY0013 (Fig. 2, Table 2). Overall, the choice of XR appeared to affect cell growth more so than 


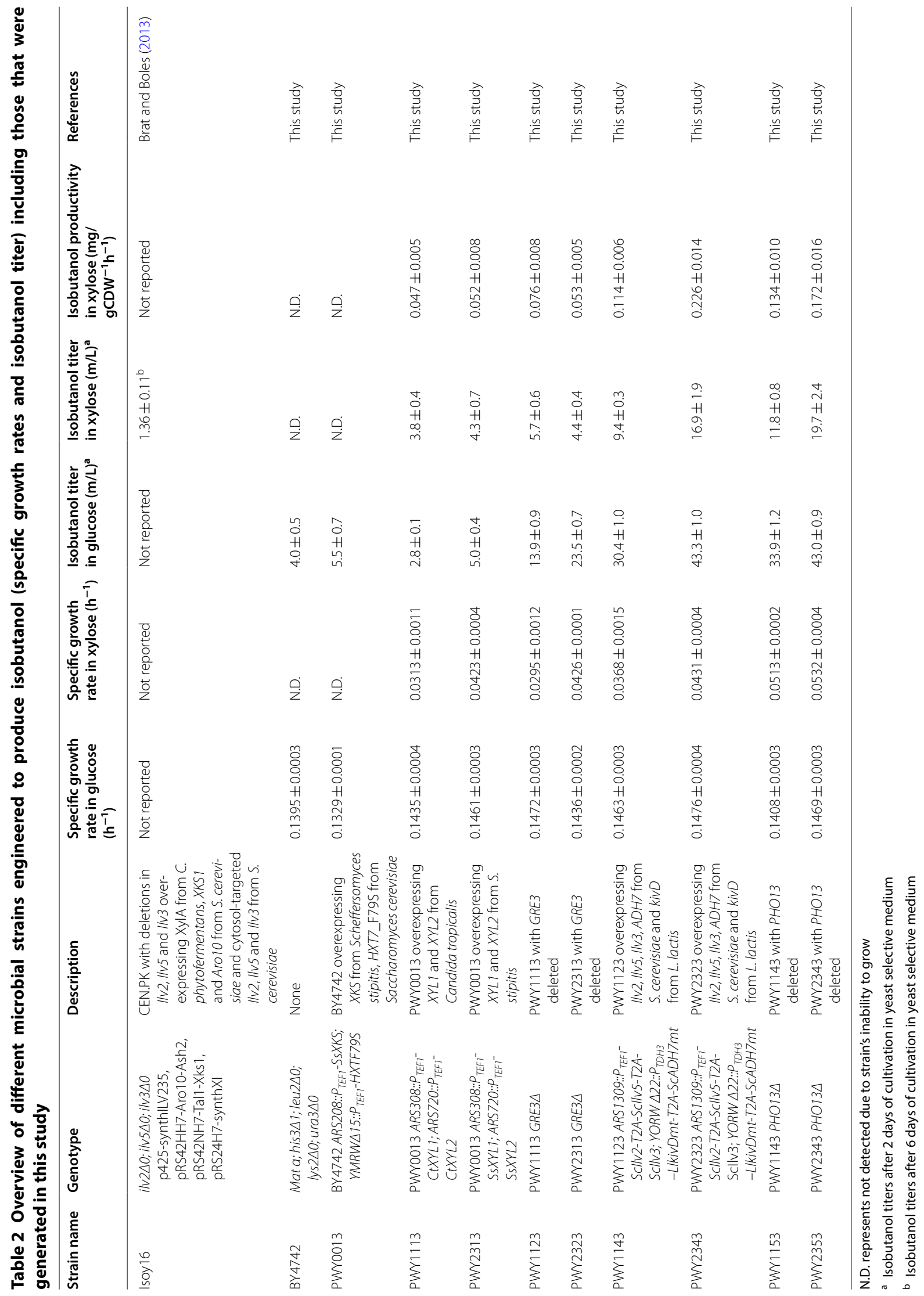




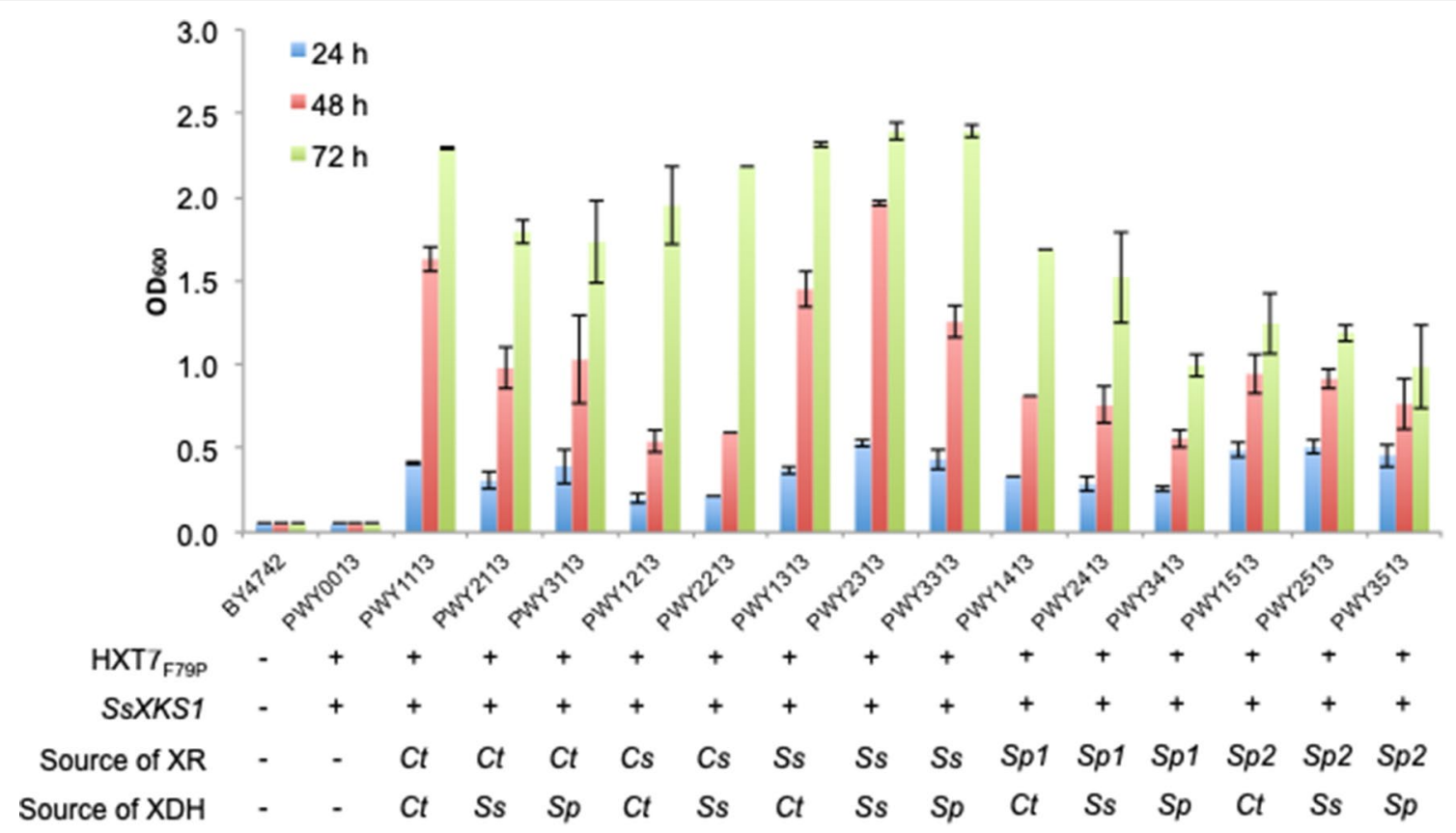

Fig. 2 Growth profile of engineered S. cerevisiae harboring different XR-XDH variants in S. cerevisiae. Engineered strains were pre-cultured in 5-mL aliquots in yeast selective medium ( $2 \%$ glucose) overnight and used to inoculate $10 \mathrm{~mL}$ yeast selective medium ( $2 \%$ xylose) to achieve an initial optical density of 0.05 at $600 \mathrm{~nm}\left(\mathrm{OD}_{600}\right)$. The cultures were grown at $30^{\circ} \mathrm{C}$ and $250 \mathrm{rpm}$ in an orbital shaking incubator. Samples were taken at 24,48 and $72 \mathrm{~h}$ time points for $\mathrm{OD}_{600}$ measurement. Values are the mean of three biological replicates \pm standard deviation $(\mathrm{n}=3)$. $\mathrm{Ct}, \mathrm{Candida}$ tropicalis; CS, Candida shehatae; SS, Scheffersomyces stipitis; Sp, Spathaspora passalidarum; Sp1, Spathaspora passalidarum XYL1.1; Sp2, Spathaspora passalidarum XYL1.2

the choice of XDH. In particular, strains expressing XR from $S$. stipitis performed the best, reaching the final $\mathrm{OD}_{600}$ (after $72 \mathrm{~h}$ ) of 2.32-2.40, while strains harboring either XR variants from S. passalidarum performed the worst, reaching the final $\mathrm{OD}_{600}$ of $0.99-1.69$. Interestingly, strains harboring XR from C. shehatae grew slowly within the first $48 \mathrm{~h}$, reaching an $\mathrm{OD}_{600}$ of $\sim 0.5$, but then grew rapidly in the final $24 \mathrm{~h}$ to reach an $\mathrm{OD}_{600}$ of 2.0 2.2. Despite several attempts, we were unable to obtain a viable strain overexpressing $\mathrm{XR}$ from $C$. shehatae and XDH from S. passalidarum. Strains PWY2313, which harbors XR and XDH from S. stipitis, and PWY1113, which harbors XR and XDH from C. tropicalis, achieved the highest $\mathrm{OD}_{600}$ after $48 \mathrm{~h}$ at 1.96 and 1.63 , respectively, and were used in subsequent engineering steps.

\section{Integration of isobutanol pathway genes for production of isobutanol from xylose}

To engineer isobutanol production in the yeast $S$. cerevisiae, we integrated the non-fermentative isobutanol pathway that combines the L-valine biosynthetic and ketoacid degradation pathways (Fig. 1). In deciding the localization of the isobutanol pathway enzymes, we contend that targeting the five enzymes to the mitochondria is a more appropriate strategy. Growth on xylose and other non-fermentable sugars has been shown to dis-regulate glucose-dependent repression of mitochondria development and induce its metabolism (DeRisi et al. 1997; Egner et al. 2002). For the choice of the keto-acid degradation pathway enzymes, we chose the keto-acid decarboxylase LlkivD from L. lactis and the endogenous alcohol dehydrogenase ADH7 based on a previous report by Avalos and co-workers that demonstrated robust activities of the two enzymes when they were both targeted to the mitochondria (Avalos et al. 2013). To incorpotate the isobutanol pathway into PWY1113 and PWY2313, we linked genes from each pathway together with the self-cleaving 2A peptide sequence from the foot-and-mouth disease virus (FMDV) (Ryan and Drew 1994) and separately placed them behind the strong constitutive promoters $\mathrm{P}_{\mathrm{TEF} 1}$ and $\mathrm{P}_{\mathrm{TDH} 3}$. This ensures stoichiometric production of all the proteins whose genes are linked together by the $2 \mathrm{~A}$ peptide sequence. The mitochondrial signal peptide sequence was added to $L l k i v D$ and $A D H 7$ to target the enzymes to the mitochondria. Finally, to increase xylose utilization, we deleted the endogenous aldose reductase gene GRE3 as well as the alkaline phosphatase gene $P H O 13$. These deletions have been used to improve xylose utilization in $S$. cerevisiae expressing either the XR-XDH or XI pathway (Karhumaa et al. 2007). 


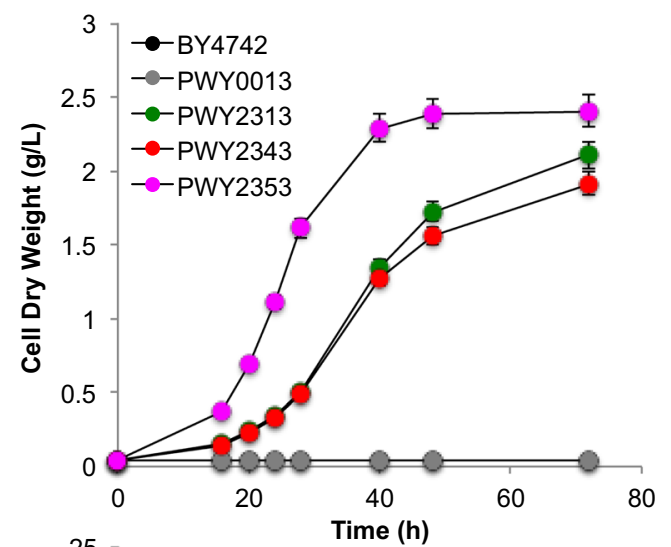

c

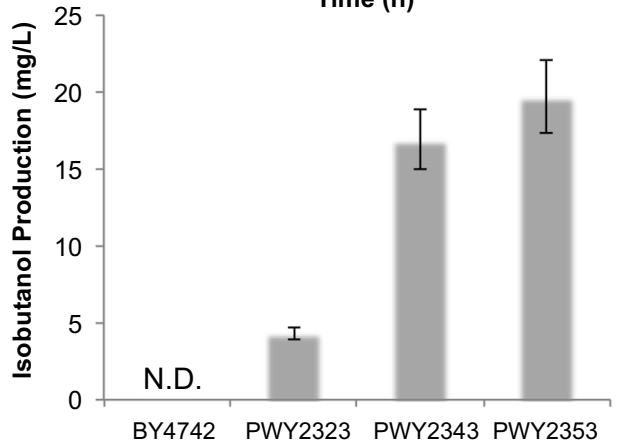

。

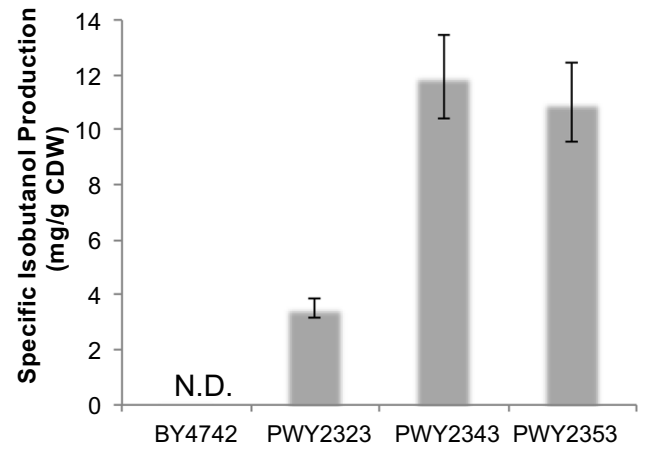

b

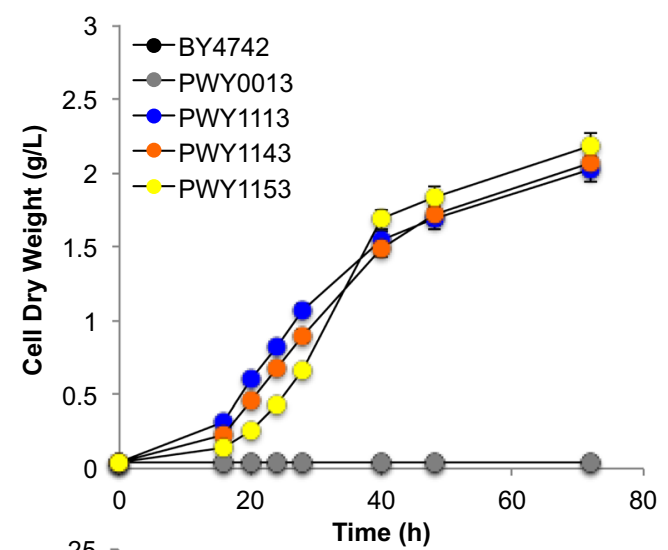

d

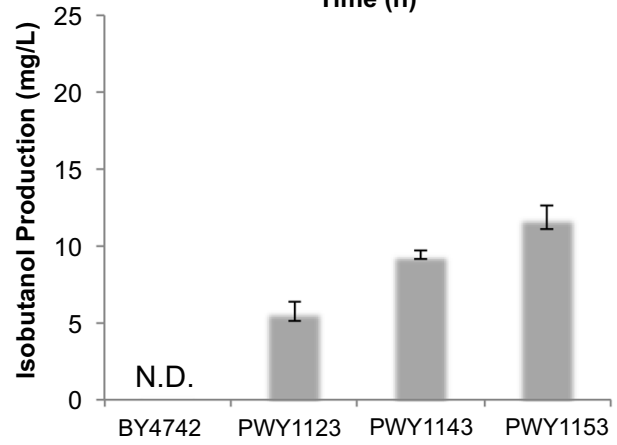

$\mathbf{f}$

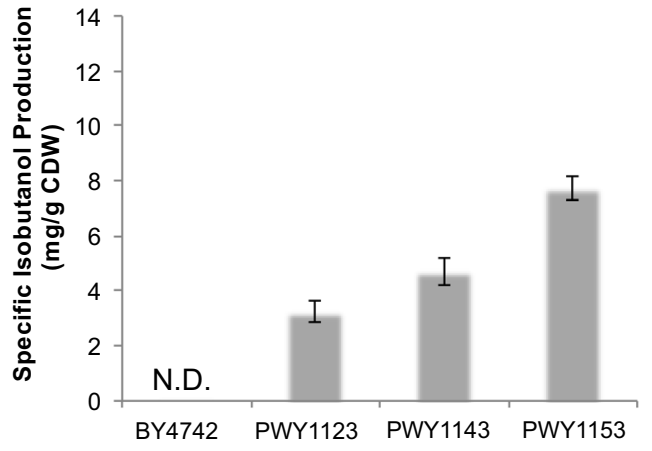

Fig. 3 Growth profile and isobutanol production of engineered strains in selective medium containing 2\% xylose. Growth profiles of engineered strains expressing XR-XDH from S. stipitis (a) and C. tropicalis (b). Total (c) and specific (e) isobutanol production after 2 days of engineered strains expressing XR-XDH from S. stipitis. Total (d) and specific (f) isobutanol production after 2 days of engineered strains expressing XR-XDH from C. tropicalis. Engineered strains were pre-cultured in 5-mL aliquots in SD selective medium overnight and used to inoculate $10 \mathrm{~mL}$ fresh SX (2\% xylose) to achieve an initial optical density of 0.05 at $600 \mathrm{~nm}\left(\mathrm{OD}_{600}\right)$. The cultures were grown at $30^{\circ} \mathrm{C}$ and $250 \mathrm{rpm}$ in an orbital shaking incubator. Samples were taken after 2 days and the supernatants were analyzed on HPLC to quantify the isobutanol content. Values are the mean of three biological replicates \pm standard deviation $(n=3)$. N.D. represents not detected due to strain's inability to grow. LI, Lactococcus lactis; SC, Saccharomyces cerevisiae; Ss, Scheffersomyces stipitis; Ct, Candida tropicalis 
Gratifyingly, we observed isobutanol production in our engineered strains (Fig. 3, Table 2). Overall, strains overexpressing XR and XDH from S. stipitis performed better, resulting in greater cell growth and higher isobutanol levels. In particular, strain PWY2343, which expresses $\mathrm{XR}$ and $\mathrm{XDH}$ from $S$. stipitis as well as the complete isobutanol pathway, produced $16.9 \pm 1.9 \mathrm{mg} / \mathrm{L}$ of isobutanol (specific isobutanol production of $11.9 \pm 1.5 \mathrm{mg} / \mathrm{g} \mathrm{CDW}$; specific growth in xylose of $0.0431 \pm 0.0004 \mathrm{~h}^{-1}$ ) after 2 days of cultivation. The deletion of $\mathrm{PHO} 13$ in strain PWY2343 to create strain PWY2353 further improved isobutanol titer to $19.7 \pm 2.4 \mathrm{mg} / \mathrm{L}$ (specific isobutanol production of $11.0 \pm 1.4 \mathrm{mg} / \mathrm{g}$ CDW; specific growth in xylose of $0.0532 \pm 0.0004 \mathrm{~h}^{-1}$ ). In comparison, the most effective strain expressing $\mathrm{XR}$ and $\mathrm{XDH}$ from $C$. tropicalis (strain PWY1353) produced isobutanol at a titer of only $11.8 \pm 0.8 \mathrm{mg} / \mathrm{L}$ (specific isobutanol production of $7.7 \pm 0.4 \mathrm{mg} / \mathrm{g} C D W$; specific growth in xylose of $\left.0.0513 \pm 0.0002 \mathrm{~h}^{-1}\right)$.

\section{Improving isobutanol titer by fine-tuning the expression levels of the biosynthetic pathway genes}

To further improve the isobutanol production titer in PWY2353, we turned our attention to fine-tuning the expression levels of the biosynthetic pathway genes. Specifically, we studied the effect of additional copies of the $\mathrm{XR}-\mathrm{XDH}$ pathway genes, the isobutanol pathway genes, as well as the transporter and xylulokinase genes. We used the CEN6/ARS4 and $2 \mu \mathrm{m}$ plasmid-expression for low and high-copy expression, respectively (Chee and Haase 2012). The yeast CEN6/ARS4 origin of replication should result in transformants with a low copy plasmid number ( 1 copy per cell). In contrast, the yeast $2 \mu$ origin of replication allows autonomous replication of the plasmids and is expected to result in transformants with a high plasmid copy number (10-40 copies per cell). We also extended fermentation time to 6 days to increase isobutanol titer as well as to allow a more direct comparison to the previous report by Brat and Boles (2013).

We obtained mixed success with high-copy plasmidbased overexpression (Fig. 4). Notably, high-copy plasmid-based expression of $L l$ kivD and ScADH7 led to the highest total isobutanol production at $47.7 \pm 5.0 \mathrm{mg} / \mathrm{L}$, a $45 \%$ increase from the control strain (PWY2353 harboring an empty high-copy vector) at $32.9 \pm 1.7 \mathrm{mg} / \mathrm{L}$ after 6 days of cultivation. This improved strain (PWY2343 harboring pRSII426-LlkivD-ScADH7) consumed more xylose and produced lower levels of the side products glycerol and xylitol. In contrast, additional copies of either $\mathrm{HXT7}_{\mathrm{F} 79 \mathrm{~S}}$ or SsXDH resulted in less xylose consumption as well as decreases in total isobutanol production $(21.9 \pm 1.5 \mathrm{mg} / \mathrm{L}$ and $25.5 \pm 4.6 \mathrm{mg} / \mathrm{L}$, respectively).
We observed similar results with low-copy plasmidbased expression (Fig. 5). Specifically, overexpression of $L$ lkivD and ScADH7 improved isobutanol titer to $48.4 \pm 2.0 \mathrm{mg} / \mathrm{L}$ (specific isobutanol production of $25.3 \pm 2.8 \mathrm{mg} / \mathrm{g}$ CDW; yield of $7.0 \mathrm{mg} / \mathrm{g}$ consumed D-xylose), which is $40 \%$ higher than in the control strain (PWY2343 harboring an empty vector) and approximately 36-folds higher than that from the previous report by Brat and Boles (total isobutanol production of $1.36 \pm 0.11 \mathrm{mg} / \mathrm{L}$ after $146 \mathrm{~h}$ of cultivation). The increase in isobutanol of this strain (PWY2343 harboring pRSII416- $L$ lkivD-ScADH7) was accompanied by a decrease in the formation of the side products ethanol and glycerol (Fig. 5), while biomass, xylose consumption and xylitol formation remained unchanged. Accumulatively, our results from both high-copy and low-copy plasmid-based overexpression indicate that overexpression of the terminal enzymes (i.e. those leading directly to the final product isobutanol) had the largest effect on isobutanol titers.

Another engineered strain of note is PWY2353 overexpressing SsXR (PWY2353 harboring pRSII416SsXR), which had the highest xylose consumption at $13.0 \pm 0.5 \mathrm{~g} / \mathrm{L}$ xylose, roughly twice the amount consumed in the control strain (at $6.8 \pm 0.6 \mathrm{~g} / \mathrm{L}$ ). However, this increase in xylose consumption did not improve isobutanol production, but rather led to increases in the formation of the pathway intermediate xylitol $(2.6 \pm 0.2 \mathrm{~g} / \mathrm{L}$ up from $1.2 \pm 0.2 \mathrm{~g} / \mathrm{L})$ and the side product ethanol $(1.4 \pm 0.1 \mathrm{~g} / \mathrm{L}$ up from $0.5 \pm 0.1 \mathrm{~g} / \mathrm{L})$. XR catalyzes the reduction of xylose to xylitol and accumulation of xylitol indicates that the next enzyme in the pathway, xylitol dehydrogenase (XDH) may be limited. Accumulation of ethanol indicates that the reduction of xylose to xylitol by XR potentially caused redox cofactor imbalances. Therefore, further strain improvement may be achieved by overexpression of an engineered $\mathrm{XDH}$ that has a cofactor preference for $\mathrm{NADP}^{+}$(Ehrensberger et al. 2006; Watanabe et al. 2007). Alternatively, down-regulation of the ethanol pathway by deleting the pyruvate decarboxylase gene PDC1 and the alcohol dehydrogenase genes ADH1-5 may further improve the isobutanol titer (Baek et al. 2017).

\section{Discussion}

Recent work on the design and construction of robust cell factories for efficient conversion of xylose into biofuels can be grouped into four complementary strategies: (1) introduction of a xylose assimilation pathway that is stoichiometrically advantageous with regards to the biofuel of interest; (2) introduction of a xylose-specific transporter; (3) introduction of specific gene knockouts to improve xylose utilization; and (4) incorporation of 

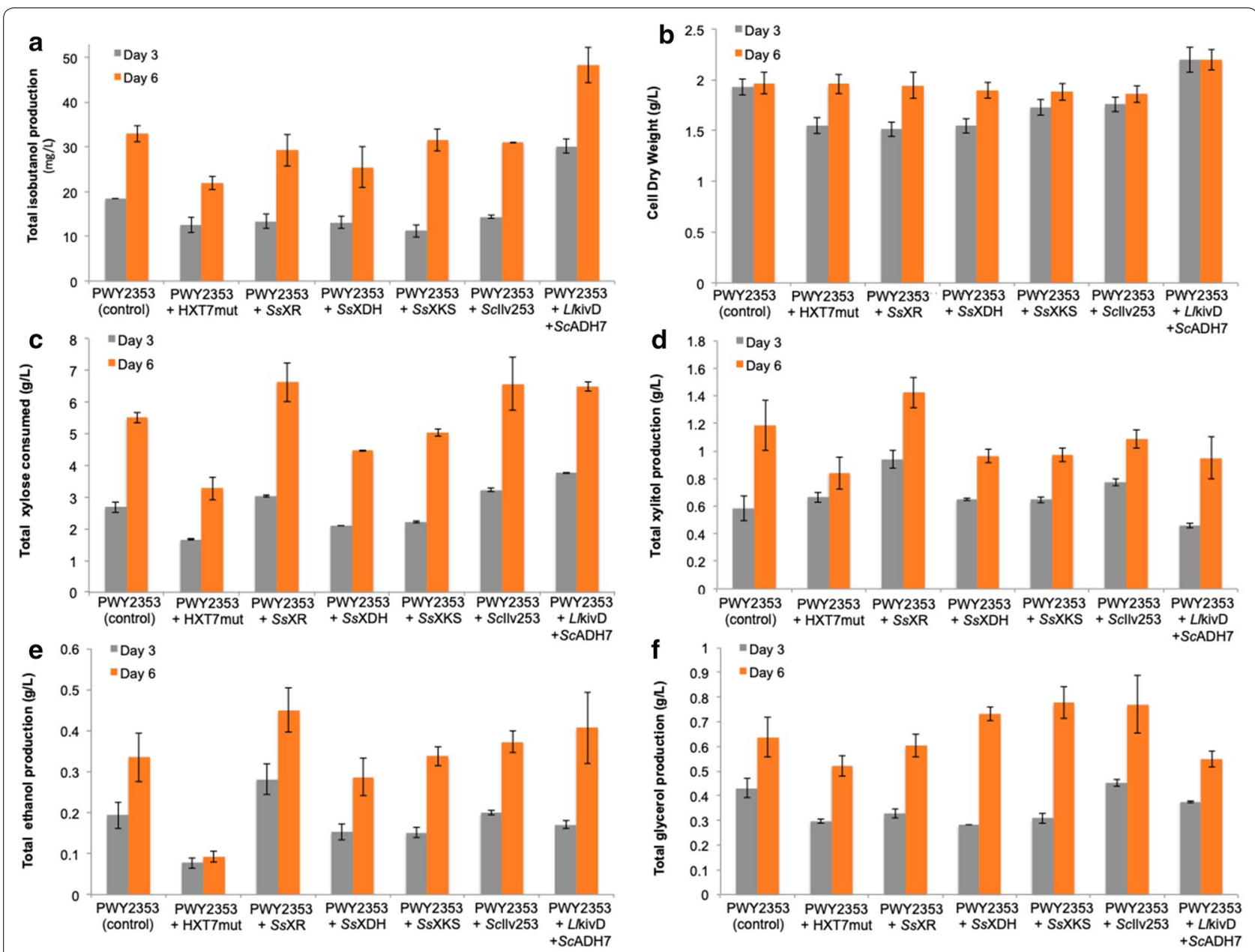

Fig. 4 Characterization of engineered strains with high-copy $(2 \mu \mathrm{m})$ plasmid-based overexpression of individual pathway genes. Total isobutanol production (a), cell dry weight (b), xylose consumption (c), xylitol production (d), ethanol production (e), and glycerol production (f). Individual gene construct was placed in the pRSII426 plasmid and transform into PWY2353. The resulting strains were cultured in selective medium containing $2 \%$ xylose as the sole carbon source. Values are the mean of three biological replicates \pm standard deviation $(n=3)$ after 3 and 6 days

the desired biofuel pathway (Kwak and Jin 2017; Li et al. 2019). We designed our isobutanol producing strain by combining these strategies.

For the first strategy, we used the conventional xylose reductase-xylose dehydrogenase pathway as it has a higher pyruvate yield based on stoichiometry when compared with the xylulose-1-phosphate (X-1-P) pathway (1.67 vs. $1 \mathrm{~mol} / \mathrm{mol}$ xylose) (Cam et al. 2016). The synthetic X-1-P pathway, which converts xylose into xylulose-1-phosphate, before an aldolytic cleavage produces glycolaldehyde and dihydroxyacetone phosphate (DHAP), is more advantageous for the production of $\mathrm{C} 2$ chemicals such as ethylene glycol (Chomvong et al. 2016). The xylose isomerase (XI) pathway, while having a similar pyruvate yield as the $\mathrm{XR}-\mathrm{XDH}$ pathway, suffers from low catalytic efficiency of the isomerase enzyme as well as the difficulty of functionally expressing bacterial
XI enzymes in S. cerevisiae (Sarthy et al. 1987; Amore et al. 1989; Moes et al. 1996). To determine the optimal $\mathrm{XR}-\mathrm{XDH}$ combination, we screened different $\mathrm{XR}$ and $\mathrm{XDH}$ variants from several xylose-utilizing yeasts.

For the second strategy, we introduced a re-engineered hexose transporter HXT7 into S. cerevisiae (Reider Apel et al. 2016). Apel and coworkers discovered a F79S point mutation in HXT7 that enables the hexose transporter to transport xylose into the cell with high efficiency. For the third strategy, we disrupted the aldose reductase gene GRE3 and the alkaline phosphatase $\mathrm{PHO} 13$ as previous reports indicated that deletion of these genes improved xylose utilization (Parreiras et al. 2014; Xu et al. 2016). Finally, for the last strategy, we overexpressed mitochondria-targeted isobutanol pathway enzymes. Applying all of these strategies resulted in strain PWY2353, which is able to produce isobutanol at a titer of $19.7 \pm 2.4 \mathrm{mg} / \mathrm{L}$ in 

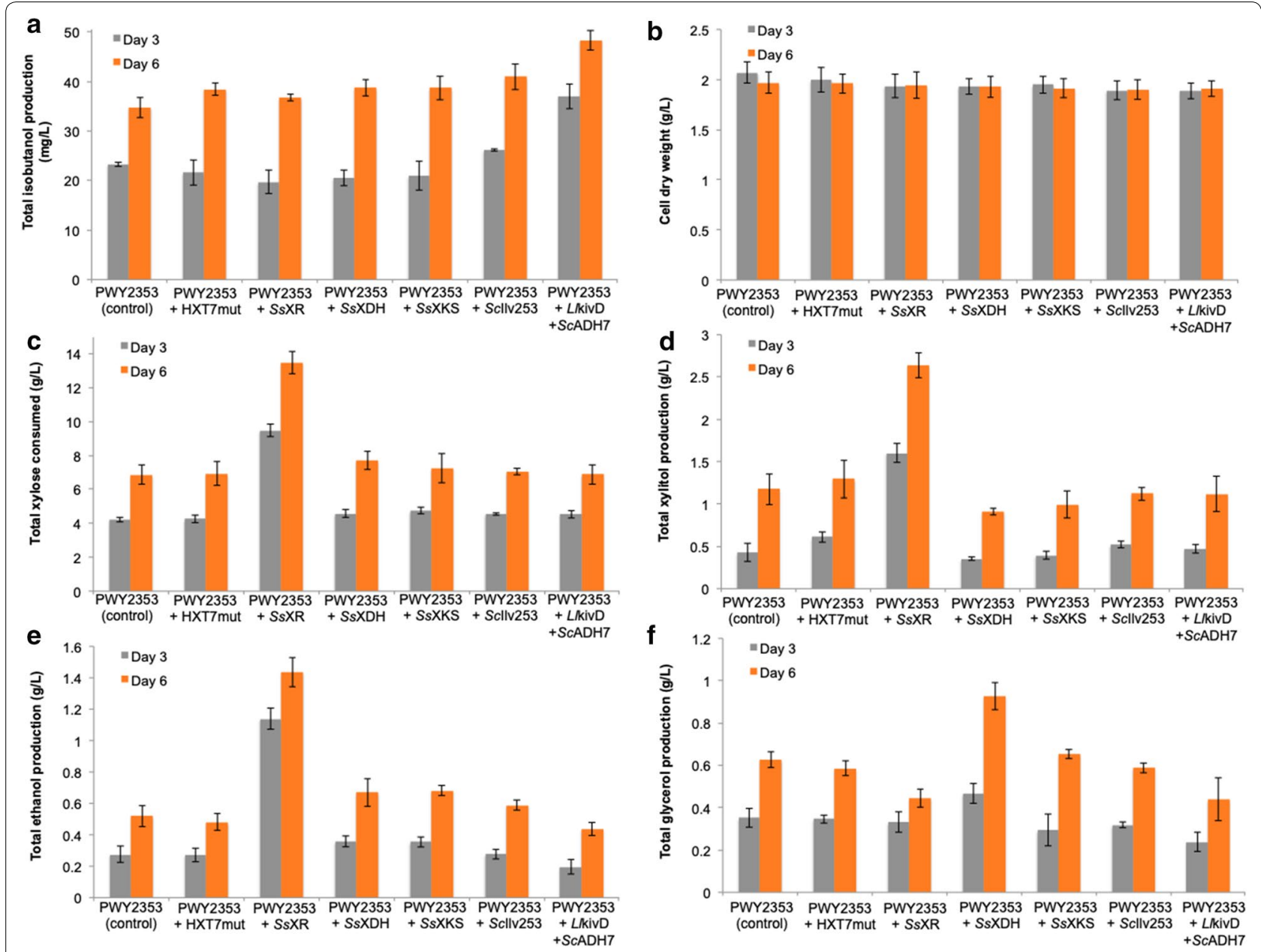

Fig. 5 Characterization of engineered strains with low-copy plasmid-based overexpression of individual pathway genes. Total isobutanol production (a), cell dry weight (b), xylose consumption (c), xylitol production (d), ethanol production (e), and glycerol production (f). Individual gene construct was placed in the pRSII416 plasmid and transform into PWY2353. All strains were cultured in selective medium containing $2 \%$ xylose as the sole carbon source. Values are the mean of three biological replicates \pm standard deviation $(n=3)$ after 3 and 6 days

$48 \mathrm{~h}$ (specific isobutanol production of $11.0 \pm 1.4 \mathrm{mg} / \mathrm{g}$ CDW; specific growth in xylose of $0.0532 \pm 0.0004 \mathrm{~h}^{-1}$ ).

We further improved strain PWY2353 by fine-tuning the expression levels of the individual biosynthetic pathway genes. A large body of work in metabolic engineering indicates that the expression levels of metabolic pathway genes greatly impact the production levels of the compound of interest (Lee et al. 2012). Too low expression levels lead to bottlenecks while too high expression levels can deplete the cellular resources that could otherwise be used to produce the compound of interest. Fine-tuning of the pathway enzyme expression levels was achieved by adding additional gene copies via the use of CEN6/ARS4 (low-copy) and $2 \mu \mathrm{m}$ (highcopy) plasmid expression systems. In both systems, we observed the biggest improvements in isobutanol production when the final two enzymes ( $L l$ kivD and ScADH7) were overexpressed. Notably, this "pulling" on the pathway by expressing the terminal enzyme is a common and effective strategy to pull flux towards the desired product as part of the "push-pull-block" strategy (Tai and Stephanopoulos 2013). Our best producer, strain PWY2353 with additional low-copy plasmidbased expression of $L l$ kivD and $S c A D H 7$, was able to produce isobutanol at a titer of $48.4 \pm 2.0 \mathrm{mg} / \mathrm{L}$ after 6 days of cultivation (specific isobutanol production of $25.3 \pm 2.8 \mathrm{mg} / \mathrm{g}$ CDW; yield of $7.0 \mathrm{mg} / \mathrm{g}$ consumed D-xylose). To our knowledge, these are the highest isobutanol titer and yield from xylose reported in any microorganism, natural or engineered. While these values are lower when compared to isobutanol production systems based on glucose, given that xylose comprises a large portion of biomass, our work provides a 
foundational step towards more sustainable and efficient production of advanced biofuels.

\section{Supplementary information}

Supplementary information accompanies this paper at https://doi. org/10.1186/s13568-019-0885-3.

Additional file 1. Information about primers and plasmids used in this study.

\section{Acknowledgements}

This work conducted by the National Center for Genetic Engineering and Biotechnology was supported by the Thailand Research Fund (TRF) under Contract No. TRG6180006.

\section{Authors' contributions}

PP designed the study, carried out most of the strain construction and characterization, and drafted the manuscript. WS and JJD contributed to the strain and plasmid construction. ST contributed to the experimental design and drafted the manuscript. WR conceived and designed the study, and drafted the manuscript. All authors read and approved the final manuscript.

\section{Funding}

This work was funded by the Thailand Research Fund (TRF) under Contract No. TRG6180006.

\section{Availability of data and materials}

All datasets on which the conclusions of the manuscript rely are presented in the main paper and additional information.

\section{Ethics approval and consent to participate}

This work does not contain any studies with human participants or animals.

\section{Consent for publication}

Not applicable.

\section{Competing interests}

The authors declare that they have no known competing financial interests or personal relationships that could have appeared to influence the work reported in this paper.

\section{Author details}

${ }^{1}$ National Center for Genetic Engineering and Biotechnology, 113 Thailand Science Park, Paholyothin Road, Klong 1, Klong Luang, Pathumthani 12120, Thailand. ${ }^{2}$ University of Kent, Canterbury, Kent, UK. ${ }^{3}$ Present Address: Syngenta, Jealott's Hill International Research Station, Bracknell, Berkshire RG42 6EY, UK.

Received: 16 July 2019 Accepted: 24 September 2019

Published online: 10 October 2019

\section{References}

Amore R, Wilhelm M, Hollenberg CP (1989) The fermentation of xylose-an analysis of the expression of Bacillus and Actinoplanes xylose isomerase genes in yeast. Appl Microbiol Biotechnol 30:351-357

Atsumi S, Hanai T, Liao JC (2008) Non-fermentative pathways for synthesis of branched-chain higher alcohols as biofuels. Nature 451:86-89

Atsumi S, Higashide W, Liao JC (2009) Direct photosynthetic recycling of carbon dioxide to isobutyraldehyde. Nat Biotechnol 27:1177-1180

Avalos JL, Fink GR, Stephanopoulos G (2013) Compartmentalization of metabolic pathways in yeast mitochondria improves the production of branched-chain alcohols. Nat Biotechnol 31:335-341

Baek SH, Kwon EY, Bae SJ, Cho BR, Kim SY, Hahn JS (2017) Improvement of $\mathrm{D}$-lactic acid production in Saccharomyces cerevisiae under acidic conditions by evolutionary and rational metabolic engineering. Biotechnol J 12:1700015

Baker Brachmann C, Davies A, Cost GJ, Caputo E, Li J, Hieter P, Boeke JD (1998) Designer deletion strains derived from Saccharomyces cerevisiae S288C: a useful set of strains and plasmids for PCR-mediated gene disruption and other applications. Yeast 14:115-132

Boeke JD, LaCroute F, Fink GR (1984) A positive selection for mutants lacking orotidine-5'-phosphate decarboxylase activity in yeast: 5-fluoro-orotic acid resistance. Mol Gen Genet 197:345-346

Brat D, Boles E (2013) Isobutanol production from D-xylose by recombinant Saccharomyces cerevisiae. FEMS Yeast Res 13:241-244

Buijs NA, Zhou YJ, Siewers V, Nielsen J (2015) Long-chain alkane production by the yeast Saccharomyces cerevisiae. Biotechnol Bioeng 112:1275-1279

Cam Y, Alkim C, Trichez D, Trebosc V, Vax A, Bartolo F, Besse P, Francois JM, Walther T (2016) Engineering of a synthetic metabolic pathway for the assimilation of (D)-xylose into value-added chemicals. ACS Synth Biol 5:607-618

Chee MK, Haase SB (2012) New and redesigned pRS plasmid shuttle vectors for genetic manipulation of Saccharomyces cerevisiae. G3 (Bethesda) 2:515-526

Choi YJ, Lee SY (2013) Microbial production of short-chain alkanes. Nature 502:571-574

Chomvong K, Bauer S, Benjamin DI, Li X, Nomura DK, Cate JH (2016) Bypassing the pentose phosphate pathway: towards modular utilization of xylose. PLOS ONE 11:e0158111

DeRisi JL, lyer VR, Brown PO (1997) Exploring the metabolic and genetic control of gene expression on a genomic scale. Science 278:680-686

Egner A, Jakobs S, Hell SW (2002) Fast 100-nm resolution three-dimensional microscope reveals structural plasticity of mitochondria in live yeast. Proc Natl Acad Sci USA 99:3370-3375

Ehrensberger AH, Elling RA, Wilson DK (2006) Structure-guided engineering of xylitol dehydrogenase cosubstrate specificity. Structure 14:567-575

Flores A, Wang X, Nielsen DR (2019) Recent trends in integrated bioprocesses: aiding and expanding microbial biofuel/biochemical production. Curr Opin Biotechnol 57:82-87

Generoso WC, Schadeweg V, Oreb M, Boles E (2015) Metabolic engineering of Saccharomyces cerevisiae for production of butanol isomers. Curr Opin Biotechnol 33:1-7

Gietz RD, Schiestl RH (2007a) Frozen competent yeast cells that can be transformed with high efficiency using the LiAc/SS carrier DNA/PEG method. Nat Protoc 2:1-4

Gietz RD, Schiestl RH (2007b) High-efficiency yeast transformation using the LiAc/SS carrier DNA/PEG method. Nat Protoc 2:31-34

Gueldener U, Heinisch J, Koehler GJ, Voss D, Hegemann JH (2002) A second set of loxP marker cassettes for Cre-mediated multiple gene knockouts in budding yeast. Nucleic Acids Res 30:e23

Guo W, Sheng J, Zhao H, Feng X (2016) Metabolic engineering of Saccharomyces cerevisiae to produce 1-hexadecanol from xylose. Microb Cell Fact 15:24

Hegemann JH, Heick SB (2011) Delete and repeat: a comprehensive toolkit for sequential gene knockout in the budding yeast Saccharomyces cerevisiae. Methods Mol Biol 765:189-206

Johansson B, Christensson C, Hobley T, Hahn-Hagerdal B (2001) Xylulokinase overexpression in two strains of Saccharomyces cerevisiae also expressing xylose reductase and xylitol dehydrogenase and its effect on fermentation of xylose and lignocellulosic hydrolysate. Appl Environ Microbiol 67:4249-4255

Karhumaa K, Garcia Sanchez R, Hahn-Hagerdal B, Gorwa-Grauslund MF (2007) Comparison of the xylose reductase-xylitol dehydrogenase and the xylose isomerase pathways for xylose fermentation by recombinant Saccharomyces cerevisiae. Microb Cell Fact 6:5

Kim SR, Skerker JM, Kang W, Lesmana A, Wei N, Arkin AP, Jin YS (2013) Rational and evolutionary engineering approaches uncover a small set of genetic changes efficient for rapid xylose fermentation in Saccharomyces cerevisiae. PLOS ONE 8:e57048

Kwak S, Jin YS (2017) Production of fuels and chemicals from xylose by engineered Saccharomyces cerevisiae: a review and perspective. Microb Cell Fact 16:82

Lamsen EN, Atsumi S (2012) Recent progress in synthetic biology for microbial production of C3-C10 alcohols. Front Microbiol 3:196 
Lee JW, Na D, Park JM, Lee J, Choi S, Lee SY (2012) Systems metabolic engineering of microorganisms for natural and non-natural chemicals. Nat Chem Biol 8:536-546

Li X, Park A, Estrela R, Kim SR, Jin YS, Cate JH (2016) Comparison of xylose fermentation by two high-performance engineered strains of Saccharomyces cerevisiae. Biotechnol Rep (Amst) 9:53-56

Li X, Chen Y, Nielsen J (2019) Harnessing xylose pathways for biofuels production. Curr Opin Biotechnol 57:56-65

Liao JC, Mi L, Pontrelli S, Luo S (2016) Fuelling the future: microbial engineering for the production of sustainable biofuels. Nat Rev Microbiol 14:288-304

Lu J, Brigham CJ, Gai CS, Sinskey AJ (2012) Studies on the production of branched-chain alcohols in engineered Ralstonia eutropha. Appl Microbiol Biotechnol 96:283-297

Matsuda F, Ishii J, Kondo T, Ida K, Tezuka H, Kondo A (2013) Increased isobutanol production in Saccharomyces cerevisiae by eliminating competing pathways and resolving cofactor imbalance. Microb Cell Fact 12:119

Moes CJ, Pretorius IS, van Zyl WH (1996) Cloning and expression of the Clostridium thermosulfurogenes D-xylose isomerase gene (xyLA) in Saccharomyces cerevisiae. Biotech Lett 18:269-274

Mosier N, Wyman C, Dale B, Elander R, Lee YY, Holtzapple M, Ladisch M (2005) Features of promising technologies for pretreatment of lignocellulosic biomass. Bioresour Technol 96:673-686

Moyses DN, Reis VC, de Almeida JR, de Moraes LM, Torres FA (2016) Xylose Fermentation by Saccharomyces cerevisiae: challenges and Prospects. Int J Mol Sci 17:207

Parreiras LS, Breuer RJ, Avanasi Narasimhan R, Higbee AJ, La Reau A, Tremaine M, Qin L, Willis LB, Bice BD, Bonfert BL, Pinhancos RC, Balloon AJ, Uppugundla N, Liu T, Li C, Tanjore D, Ong IM, Li H, PohImann EL, Serate J, Withers ST, Simmons BA, Hodge DB, Westphall MS, Coon JJ, Dale BE, Balan V, Keating DH, Zhang Y, Landick R, Gasch AP, Sato TK (2014) Engineering and two-stage evolution of a lignocellulosic hydrolysate-tolerant Saccharomyces cerevisiae strain for anaerobic fermentation of xylose from AFEX pretreated corn stover. PLoS ONE 9:e107499

Peralta-Yahya PP, Ouellet M, Chan R, Mukhopadhyay A, Keasling JD, Lee TS (2011) Identification and microbial production of a terpene-based advanced biofuel. Nat Commun 2:483

Peralta-Yahya PP, Zhang F, del Cardayre SB, Keasling JD (2012) Microbial engineering for the production of advanced biofuels. Nature 488:320-328

Reider Apel A, Ouellet M, Szmidt-Middleton H, Keasling JD, Mukhopadhyay A (2016) Evolved hexose transporter enhances xylose uptake and glucose/ xylose co-utilization in Saccharomyces cerevisiae. Sci Rep 6:19512
Reider Apel A, d'Espaux L, Wehrs M, Sachs D, Li RA, Tong GJ, Garber M, Nnadi O, Zhuang W, Hillson NJ, Keasling JD, Mukhopadhyay A (2017) A Cas9-based toolkit to program gene expression in Saccharomyces cerevisiae. Nucleic Acids Res 45:496-508

Runguphan W, Keasling JD (2014) Metabolic engineering of Saccharomyces cerevisiae for production of fatty acid-derived biofuels and chemicals. Metab Eng 21:103-113

Ryan MD, Drew J (1994) Foot-and-mouth disease virus 2A oligopeptide mediated cleavage of an artificial polyprotein. EMBO J 13:928-933

Sarthy AV, McConaughy BL, Lobo Z, Sundstrom JA, Furlong CE, Hall BD (1987) Expression of the Escherichia coli xylose isomerase gene in Saccharomyces cerevisiae. Appl Environ Microbiol 53:1996-2000

Schneider JC, Guarente L (1991) Vectors for expression of cloned genes in yeast: regulation, overproduction, and underproduction. Methods Enzymol 194:373-388

Siripong W, Wolf P, Kusumoputri TP, Downes JJ, Kocharin K, Tanapongpipat S, Runguphan W (2018) Metabolic engineering of Pichia pastoris for production of isobutanol and isobutyl acetate. Biotechnol Biofuels 11:1

Tai M, Stephanopoulos G (2013) Engineering the push and pull of lipid biosynthesis in oleaginous yeast Yarrowia lipolytica for biofuel production. Metab Eng 15:1-9

Watanabe S, Saleh AA, Pack SP, Annaluru N, Kodaki T, Makino K (2007) Ethanol production from xylose by recombinant Saccharomyces cerevisiae expressing protein engineered $\mathrm{NADP}^{+}$-dependent xylitol dehydrogenase. J Biotechnol 130:316-319

Xu H, Kim S, Sorek H, Lee Y, Jeong D, Kim J, Oh EJ, Yun EJ, Wemmer DE, Kim KH, Kim SR, Jin YS (2016) PHO13 deletion-induced transcriptional activation prevents sedoheptulose accumulation during xylose metabolism in engineered Saccharomyces cerevisiae. Metab Eng 34:88-96

Zhang B, Sun H, Li J, Wan Y, Li Y, Zhang Y (2016) High-titer-ethanol production from cellulosic hydrolysate by an engineered strain of Saccharomyces cerevisiae during an in situ removal process reducing the inhibition of ethanol on xylose metabolism. Process Biochem 51:967-972

\section{Publisher's Note}

Springer Nature remains neutral with regard to jurisdictional claims in published maps and institutional affiliations.

\section{Submit your manuscript to a SpringerOpen ${ }^{\odot}$ journal and benefit from:}

- Convenient online submission

- Rigorous peer review

- Open access: articles freely available online

- High visibility within the field

- Retaining the copyright to your article

Submit your next manuscript at $\boldsymbol{\nabla}$ springeropen.com 